\title{
Reference data for derived Trail Making Test scores in Greek healthy population
}

\author{
Ioannis Zalonis, Fotini Christidi*, Evangelia Kararizou, Nikolaos I Triantafyllou, Elizabeth Kapaki, George Paraskevas, \\ Panagiotis Sgouropoulos, Dimitrios Vassilopoulos
}

From $1^{\text {st }}$ International Congress on Neurobiology and Clinical Psychopharmacology

and European Psychiatric Association Conference on Treatment Guidance

Thessaloniki, Greece. 19-22 November 2009

\section{Background}

The Trail Making Test (TMT) via part B (TMT-B) has been widely used in the evaluation of the executive functions [1]. Apart from the direct scores (time to complete part $\mathrm{A}$ and $\mathrm{B})$, derived TMT scores (B-A, B/A, $\mathrm{B}-\mathrm{A} / \mathrm{A})$ are more and more used, as sensitive measures of prefrontal functioning [2-4]. The aim of the present study was to provide reference data from a large sample of Greek healthy participants in derived TMT scores.

\section{Materials and methods}

Six hundred and forty-three healthy participants (aged between 16-83 yrs and with an educational level between 6-18 yrs) were included, satisfying the exclusion criteria of medical, psychiatric and neurological disorders. From the TMT performance, we further calculated the following derived scores: the difference score $(\mathrm{B}-\mathrm{A})$, the ratio score $(\mathrm{B} / \mathrm{A})$ and the proportional score (B-A/A).

\section{Results}

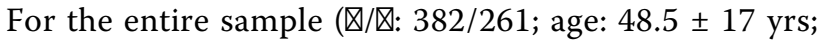
education: $12 \pm 3.5$ yrs), derived mean scores for (B-A) was $61.7 \pm 43.6$ seconds (range: $1-325$ seconds), for (B/A) was $2.3 \pm 0.8$ (range: 1-7.4), and for (B-A/A) was $1.3 \pm 0.8$ (range: 0.01-6.4). At $\mathrm{p}<.05$, age was significantly associated with $(\mathrm{B}-\mathrm{A})(\mathrm{r}=0.53),(\mathrm{B} / \mathrm{A})(\mathrm{r}=0.27)$ and $(\mathrm{B}-\mathrm{A} / \mathrm{A})$ $(r=0.27)$ scores. Significant correlations $(p<.05)$ were also emerged between years of education and the three previous mentioned derived scores $(\mathrm{r}=-0.20, \mathrm{r}=-0.13$, $r=-0.13$, respectively). Gender was unrelated to derived TMT scores $(\mathrm{r}<.05, \mathrm{p}$ n.s.). Based on post-hoc comparisons between age groups (per decade of age) and education groups (6-9 yrs, 10-12 yrs, 13-18 yrs), we stratified our sample according to age and years of education and present reference data for the three derived TMT scores as mean $(\mathrm{sd})$.

\section{Conclusions}

The Greek reference data for the derived TMT measures, stratified by age and education, are presented for application in clinical and experimental practice as useful indices in identification of probable executive dysfunction.

Published: 22 April 2010

\section{References}

1. Lezak MD, Howieson DB, Loring DW: Neuropsychological Assessment. NY Oxford University Press 2004

2. Lamberty GJP, Chatel SH, Bieliauskas DM, et al: Derived Trail Making Test indices: A preliminary report. Neuropsychiatry, Neuropsychology, \& Behavioral Neurology 1994, 7:230-234.

3. Stuss DT, Bisschop SM, Alexander MP, et al: The Trail Making Test: A study in focal lesion patients. Psychological Assessment 2001, 13:230-239.

4. Drane DL, Yuspeh RL, Huthwaite JS, et al: Demographic characteristics and normative observations for derived-trail making test indices. Neuropsychiatry, Neuropsychology and Behavioral Neurology 2002, 15:39-43.

doi:10.1186/1744-859X-9-S1-S145

Cite this article as: Zalonis et al.: Reference data for derived Trail Making Test scores in Greek healthy population. Annals of General Psychiatry 2010 9(Suppl 1):S145. 